http://dx.doi.org/10.30681/23588403v12i01162170

\title{
A VIOLÊNCIA COMO DESTINO EM JEAN GENET
}

Data de recebimento: 03/11/2017

Aceite: 07/02/2018

\section{Pedro Henrique Rodrigues da SILVA ${ }^{1}$}

\begin{abstract}
Resumo: Este artigo versa sobre a nossa compreensão da violência como destino, na escritura do poeta, escritor e dramaturgo francês, Jean Genet. Inicialmente, buscamos mostrar como a violência é uma condição da existência, refletida nos aspectos complexos e sutis dos escritos de Genet. Depois, procuramos indicar como o desejo de violência permeia a relação entre o poeta e seus personagens, mostrando-se, assim, como força de criação. Em seguida, desnudamos o corpo como possibilidade de experimentação constante, e, por vezes, extrema, seja no crime, na reclusão, no sexo ou na miséria. Por fim, agregando todos esses aspectos, acreditamos que a escritura genetiana se desvela como uma espécie de alegria trágica, na qual, por meio de uma excitação com a vida, há uma forma própria de afirmação.
\end{abstract}

Palavras-chave: Alegria Trágica; Corpo; Desejo; Vida; Violência.

Abstract: This article deals with our understanding of violence as destiny, in the writing of the French poet, writer and playwright, Jean Genet. Initially, we sought to show how violence is a condition of existence, reflected in the complex and subtle aspects of Genet's writings. Then, we try to indicate how the desire for violence permeates the relation between the poet and his characters, thus showing himself as a creative force. Then we strip the body as a possibility of constant experimentation, and sometimes extreme, whether in crime, seclusion, sex or misery. Finally, in summing up all these aspects, we believe that Genetic writing is revealed as a sort of tragic joy, in which, through an excitation with life, there is a proper form of affirmation.

Keywords: Tragic Joy; Body; Desire; Life; Violence.

\section{A violência como destino em Jean Genet}

A vida se manifesta através da violência, genuína e necessária. Isso, pois, em seus transcursos, a existência opera por meio de excessos, rupturas e destruições, obrigando-nos, consequentemente, a andejar diuturnamente por uma corda bamba. Tudo está em incessante

\footnotetext{
${ }^{1}$ Bacharel/Licenciado em filosofia pela Pontifícia Universidade Católica de Minas Gerais (PUC-MG). Mestre pelo Programa de Pós-graduação em Estudos de Linguagens do Centro Federal de Educação Tecnológica de Minas Gerais (CEFET-MG), linha de pesquisa: Literatura, Cultura e Tecnologia. Doutorando pelo Programa de Pós-graduação em Estudos de Linguagens do Centro Federal de Educação Tecnológica de Minas Gerais (CEFET-MG), linha de pesquisa: Literatura, Cultura e Tecnologia. Integrante do grupo de pesquisas Literatécnica (Literatura e Técnica), do Centro Federal de Educação Tecnológica de Minas Gerais (CEFETMG), coordenado pelo Prof. Dr. João Batista Santiago Sobrinho. Cidade de Origem: Betim-MG. País de origem: Brasil. E-mail: pedro_h_filosofia2@yahoo.com.br.
} 


\section{Revista de Estudos Acadêmicos de Letras}

vir-a-ser, atemorizando as levianas tentativas de programar a vida. Uma travessia na qual o único sentido possível é o inelutável acaso. A alegria, a dor, o horrendo, o belo, o trágico, vêm compor um complexo de indefinidas transmutações, sobre as quais a única forma legítima de se expressar é com atônito silêncio.

No momento de maturidade da cultura grega antiga - da Tragédia Ática, da filosofia Pré-socrática, e sua saúde, como Nietzsche (1987) por vezes indicou em A filosofia na idade trágica dos gregos - Heráclito, no uso de sua sensibilidade intuitiva ${ }^{2}$, já afirmava o vir-a-ser como a mais pura forma de violência, ao dizer que toda transformação nasce da eterna guerra entre os contrários. Nessa tensão entre incalculáveis forças distintas e incontroláveis, cada uma delas busca imperar sobre as demais, por mais que, sem tardar, todas, ao seu tempo, acabem sucumbindo, produzindo assim, toda mudança que ocorre.

Em Além do bem e do mal, Nietzsche (2005) diz que a vida é “[...] essencialmente apropriação, ofensa, sujeição do que é estranho e mais fraco, opressão, dureza, oposição de formas próprias e, no mínimo e mais comedido, exploração [...]” (NIETZSCHE, 2005, p. 154155). Características que qualificam as violências da vida como uma condição, e não uma opção moral. Conquanto, em uma acepção mais popular, a interpretação dos adjetivos usados pelo filósofo alemão está impregnada de uma conotação moralizada e difamadora, reputando como inadequada, a vida e o que há de mais inocente nela: os conflitos entre diferentes forças e suas exigências.

Não obstante da perspectiva nietzschiana, em Diário de um ladrão, de uma maneira afirmadora, o poeta, escritor e dramaturgo francês, Jean Genet (2005), expõe sua concepção de violência:

Dou nome de violência a uma audácia em repouso apaixonada pelo perigo. Pode ser percebida num olhar, num andar, num sorriso, e é dentro de nós que ela produz redemoinhos. Ela nos desmonta. Essa violência é uma calma que nos agita. (GENET, 2005, p. 19).

Analisando alguns aspectos biográficos de Genet, é possível reconhecer uma adesão profunda, porém necessária, às situações de criminalidade. Abandonado pela mãe quando era criança, o escritor francês recorreu aos roubos, à prostituição e às traições. Nesses intercursos, entre guetos e prisões, conheceu uma série de personagens marginalizados que se tornaram

\footnotetext{
${ }^{2}$ Em A filosofia na era trágica dos gregos, Nietzsche (1985) afirma que o dom real do filósofo de Éfeso é a "representação intuitiva", que se contrapõe a qualquer forma de representação que se "[...] efectiva em conceitos e combinações lógicas, portanto, para a razão [...]" (NIETZSCHE, 1987, p. 40). Somente com tal sensibilidade é possível contemplar o vir-a-ser, sem acusá-lo.
} 


\section{Revista de Estudos Acadêmicos de Letras}

influências para sua existência e mote fundamental de sua escritura, sobretudo nos primeiros livros. Ao tratar a violência, Jean não usa o discurso corrente, metafísico, maniqueísta, com fundamentação religiosa, que segrega o transgressor e suas ações. Ele afasta o crime do lugar da moralidade ao falar com a voz do criminoso e avocar suas motivações.

Para o poeta, a violência, como expressão da vida, é imanente, cotidiana e antagônica. Desvela-se nas corporeidades mais sutis, e que, contrariamente, provocam o que há de mais soblevado no indivíduo. Desarranja-o. O redemoinho tem forte simbologia, nesse ponto: ele é a metáfora das mais variadas formas de dilaceração do corpo, das quais Genet se vale como temática de sua criação. Os mendigos com corpos fétidos e putrefatos; as orgias nos guetos escuros e imundos de alguma cidade europeia; a vítima que sangra na ponta do punhal de seu algoz. Tudo o leva a se precipitar com entusiasmo no abismo da existência. E, ao mesmo tempo em que afaga, perturba.

Não apenas por isso, mas por outras manifestações, acreditamos que o escritor francês nutria fascínio pela violência. Os personagens expostos em seus escritos (e que permearam a vida de Genet) são indivíduos proscritos que pululam os subúrbios parisienses e de outras metrópoles mundo afora: ladrões, assassinos, michês, prostitutas, travestis e jogadores. Muitas vezes a mesma pessoa reúne vários desses papeis. Chama a atenção como eles experimentam a efemeridade do existir, no limite, mas com alegria afirmadora ao saboreá-la. E, acima de tudo, como a escritura genetiana externa-se na forma de ode à criminalidade. $\mathrm{O}$ enfrentamento ao modelo de escritura comum, formal, romantizada, moralmente bem vista, é, por si só, uma ação necessária de violência.

Nesse caminho, existe na envergadura poética genetiana a manifestação do desejo, na busca irrestrita por prazer nos usos multiformes do corpo. Um forte estímulo hedonista, que qualifica o corpo como a fonte de descobertas e do deleite primordial. Ainda em Diário de um ladrão, ao falar sobre a condição de violência dos personagens, Genet (2005) afirma o desejo que faz com que eles estejam sempre em seu imaginário:

Aqueles cuja violência é o clima habitual são simples diante de si mesmos. Dos movimentos que compõem essa vida rápida e devastadora, cada um é simples, direto, nítido, como o traço de um grande desenhista - mas no encontro desses traços em movimento estoura então a tempestade, o raio que os mata ou me mata. No entanto, o que é a violência deles ao lado da minha que foi aceitar a deles, fazê-la minha, querê-la para mim, captá-la, obrigarme a aceitá-la, conhecê-la, premeditá-la, discernindo nelas os seus perigos e assumindo-os? (GENET, 2005, p. 21). 


\section{Revista de Estudos Acadêmicos de Letras}

Para aqueles que a cultivam em suas vidas e a afirmam, a violência é um traço simples e habitual. Todavia, como uma força avassaladora, ela provoca a fugacidade, fiando a linha tênue entre a vida e a morte, incluindo a do próprio escritor. Genet questiona sobre o seu posicionamento diante da crueldade como afirmação da violência, por parte dos personagens. De maneira decisiva, o desejo liga o poeta a eles: a vontade de buscar a violência; transformála em necessidade; querer ela para si e incorporá-la, incita, desse modo, todas as suas forças de criação.

Em Micropolítica cartografias do desejo, Felix Guattari (1996) define desejo da seguinte forma:

Por não querer me atrapalhar com definições complicadas, eu proporia denominar o desejo a todas as formas de vontade de viver, de vontade de criar, de vontade de amar, de vontade de inventar uma outra sociedade, outra percepção do mundo, outros sistemas de valores. (GUATTARI, 1996, p. 215).

O desejo é, destarte, produtor de transvalorações, que revelam, por meio das inúmeras formas de aspiração, modos elaborados de produção/criação. A visão de Guattari recusa as oposições tradicionais e maniqueístas, nas quais há, de um lado, o universo abissal do desejo, que precisa ser incessantemente contido, em oposição ao universo da ordem racional, social, civilizada. Está implícito nesse olhar dualista o nexo de um paradigma de dominação, reforçado por diferentes discursos moralizados, que vê no desejo, em termos psicológicos e morais, certa coisa secreta e vergonhosa, vivida na clandestinidade, e, em termos políticos, algo utópico e anárquico.

Ora, o desejo não se liga apenas ao ser humano, já que é uma energia imanente que faz do vir-a-ser - o fluxo da existência - pura criação. No volume I de O anti-Édipo, Capitalismo e esquizofrenia, Deleuze e Guattari (2004) veem o mundo como uma máquina desejante que agrega um conjunto indefinido de outras máquinas desejantes, incluindo os corpos humanos. Nessa direção, tudo é produção ${ }^{3}$, produção de produções, de ações e reações, de distribuição de pontos de referência, de êxtases, angústias e dores. O homem e a natureza não são componentes distintos, mas uma só e mesma realidade: a do produtor e do produto, mas que também produz, e cujo princípio imanente é o desejo.

\footnotetext{
${ }^{3}$ Empregamos o termo 'produção' procurando mantê-lo tal como aparece no capítulo intitulado As máquinas desejantes (DELEUZE; GUATTARI, 2004, p. 7-52). Porém, compreendemos esse termo, não como algo ligado a uma lógica de 'produção industrial', própria do capitalismo, mas como a dinâmica de destruição e criação, própria da existência.
} 


\section{Revista de Estudos Acadêmicos de Letras}

O desejo se mostra também como desejo de morte, pois o inevitável perecimento é uma dentre tantas dimensões da vida:

Instinto de morte é o seu nome, e a morte não existe sem modelo. Porque o desejo também deseja a morte, porque o corpo pleno da morte é o seu motor imóvel, tal como deseja a vida, porque os órgãos da vida são a working machine. [...] As máquinas desejantes só funcionam avariadas, avariando-se constantemente. (DELEUZE; GUATTARI, 2004, p. 13. Grifo do autor).

Para Aristóteles, o primeiro motor imóvel estabelece um sentido para a existência, com características metafísicas, diga-se de passagem. Ao mesmo tempo, ele é fundamento e destino. Na dinâmica causal aristotélica, o primeiro motor é a causa primeira, força motriz de toda produção, direcionando tudo para um fim, (télos, na língua grega), uma noção etérea de perfeição.

Diferente disso, acreditamos que Deleuze e Guattari colocam o conceito do primeiro motor imóvel de maneira diferenciada: tudo o que vive tende à morte; tudo o que existe tende à deterioração, à destruição. É necessário ser assim para que algo novo seja criado. O corpo, emaranhado de órgãos, desgasta-se no trabalho (working machine). Eis a dinâmica do devir, ligada sempre ao plano de imanência, sem um fora fundamental, nem fixidez, e na qual tudo se transforma incessantemente. Há, assim, a clara adesão ao pensamento de Heráclito, o efésio que vê em tudo a necessidade irreparável da mudança.

Vida e morte, desejo e violência, todos perpassam pela corporeidade. Exteriorizadas em seus relatos, as vivências de Genet mostram as aplicações irrestritas do corpo por meio da criminalidade, das prisões, da miséria e do sexo. Não há outra possibilidade de existência, porquanto o que existe são relações corpóreas e nada mais: eu sou corpo, o outro é corpo, a terra é corpo.

Como exemplo, em Nossa senhora as flores, ao descrever aspectos peculiares dos prisioneiros do Centro Penitenciário de Fresnes, o escritor francês (1983) evidencia como eles experimentam uma espécie de ritual, ao se tatuarem:

A grande ocupação noturna, aquela que é admiravelmente própria para encantar a noite, é a tatuagem. Mil e mil pequenos golpes de uma fina agulha batem até sangrar a pele, e as figuras mais extravagantes que se possa imaginar são exibidos nos lugares mais inusitados. Quando o rabino desenrola lentamente a Tora, um mistério emana um arrepio através da epiderme, da mesma forma quando se vê um colono tirando a roupa. Todo o azul deformante sobre uma pele branca reveste de um prestígio obscuro, mas patente, a criança coberta por ele, como uma indiferente e pura coluna torna- 


\section{Revista de Estudos Acadêmicos de Letras}

se sacra após os entalhes dos hieróglifos. Como uma estaca Totem. Às vezes marcam-se as pálpebras, as axilas, as reentrâncias da virilha, as nádegas, o pênis, e até a palma dos pés. Os sinais eram bárbaros e tão significativos como os sinais dos povos mais bárbaros: amores-perfeitos, arcos, corações trespassados, gotejando sangue, rostos uns sobre os outros, estrelas, meiasluas, linhas, andorinhas, serpentes, barcos, punhais triangulares e inscrições, divisas, propagandas, toda uma literatura profética e terrível. (GENET, 1983, p. 232-233).

Com as formas tatuadas, o corpo inteiro se converte em obra de arte, plenamente. A representação de diferentes figuras, cada uma um símbolo com sentido íntimo. Advém, assim, uma mescla de sacramentos profanos que penetram a vida de cada prisioneiro. Uma liturgia digna das tradições tribais - maoris, samoanas, celtas - em que subjetividades são reveladas: amores, volúpias, dores, memórias. A carne, entalhada com rastros das vivências e tingida com o próprio sangue, transforma-se em uma representação de si mesma.

A escritura genetiana se transforma em eco do pensamento de Nietzsche. Ao contrário da tradição platônica e judaico-cristã que sempre nutriu desprezo pela corporeidade em nome de pretensas razões suprassensíveis, o pensador alemão buscou diuturnamente dar voz ao corpo e seus ressoadores.

Em Assim falava Zaratustra, no capítulo intitulado Ler e escrever, o filósofo alemão (2014) diz que: "De tudo quanto se escreve, agrada-me apenas o que alguém escreve com o próprio sangue. Escreve com sangue; e aprenderás que sangue é espírito.” (NITZSCHE, 2014, p. 51). Dentre os elementos do corpo, o sangue é uma metonímia das experiências. Destarte, escrever com o próprio sangue denota transpor uma escrita vazia para uma escrita valiosa, repleta de seus biografemas. Traçando paralelos possíveis, o físico tatuado dos prisioneiros com os quais Genet conviveu está repleto de sangue (de vida, de memória) que irrompe por meio da escritura do poeta francês.

Ora, por meio das tatuagens o corpo faz uma nova leitura de si mesmo, a partir de uma perspectiva estética discernida. Isso permite associarmos ao que Deleuze e Guattari (2004) inspirados por Antonin Artaud - chamam de corpo sem órgãos, ainda em anti-Édipo (dentre outros textos ${ }^{4}$ ). O organismo (a disposição usual dos órgãos) é organizado; definido por sua constituição e funcionamento; hierarquia e relações de poder. Contrariamente, o corpo sem orgãos é desordenado, propositalmente. Em busca de se recriar, anarquiza-se do normal. Multiforme, é composto somente por carne, nervos e uma gama indefinida de forças que por ele passam e o reconfiguram constantemente, fazendo-o escapar da inércia.

\footnotetext{
${ }^{4}$ O conceito de 'corpo sem orgãos' aparece inicialmente em $O$ anti-Édipo (de 1972), mas também em Mil platôs (de 1980) e Francis Bacon: lógica da sensação (de 1981), o último escrito apenas por Deleuze.
} 


\section{Revista de Estudos Acadêmicos de Letras}

Enfim, todos os aspectos tratados até aqui compõem o panorama de uma forma de felicidade, presente na escritura genetiana. Ainda em Diário de ladrão, Genet (2005) afirma que,

Nesse diário não quero dissimular as outras razões que fizeram de mim um ladrão, a mais simples sendo a necessidade de comer; todavia, em minha escolha jamais entraram a revolta, a amargura, a raiva ou qualquer sentimento desse tipo. Com um cuidado maníaco, "um cuidado ciumento", preparei minha aventura como se arruma uma cama, um quarto para o amor: eu tive tesão pelo crime. (GENET, 2005, p.18. Grifo do autor).

Os aspectos gregários da vida do poeta (comer, se vestir, um abrigo) - da de qualquer ser humano - seriam por si só um motivo suficiente para recorrer à violência, a não ser para quem a criminaliza. Nos momentos mais extremos, a necessidade se sobrepõe à razão. Porém, algo mais entranhado o dirigiu para esse caminho: uma vitalidade erotizada, não apenas na perspectiva sexual, propriamente dita, mas de uma sensualidade peculiar da criminalidade. E, nesse sentido, podemos falar de uma forma de felicidade na escritura de Genet. A afirmação do crime e suas sensações, independente do caráter; a excitação com os roubos e os ladrões, e o gozo com os assassinatos e seus feitores.

Esse ponto se aproxima com o conceito de alegria trágica, associada ao pensamento nietzschiano. Na Gaia Ciência, no parágrafo intitulado Para o novo ano, o filósofo alemão (1984) define o conceito de amor fati, expressão latina cujo significado é o amor pelo fato ou o amor pelo destino. Para o filósofo alemão, trata-se do sentimento adequado diante do devir, como condição: se não há remédio contra o inelutável, que “[...] seja esse de agora em diante o meu amor. [...] E, numa palavra em grosso, não quero, a partir de hoje, ser outra coisa senão um afirmador." (NIETZSCHE, 1984, p. 180). Ou seja, cabe ao homem compreender e afirmar o vir-a-ser.

No entanto, o amor fati se diferencia de uma aceitação com pesar. Pelo contrário, esse sentimento na afirmação se manifesta como sinal de alegria.

Em Nietzsche e a alegria do trágico, Miguel Angel de Barrenechea (2014) diferencia o trágico da seriedade e o trágico do riso e da afirmação: o primeiro se caracteriza pelo pessimismo, já o segundo se manifesta como “[...] celebração irrestrita da natureza, como explosão de risos perante a existência, perante todas as suas vicissitudes, rindo até da finitude e da morte." (BARRENECHEA, 2014, p. 130). Mas, para Barrenechea, o que isso quer dizer? Significa que para além das tragédias cotidianas, sempre há um limiar para a alegria, a leveza, 


\title{
Revista de Estudos Acadêmicos de Letras
}

a saúde. A capacidade de festejar um mundo que cria e destrói permanentemente (que nos cria e nos destrói). A alegria trágica é cultuar a capacidade de rir de forma extraordinária.

Finalmente, diante dessas afirmações, Genet se encontra entre aqueles cultivam uma espécie de alegria trágica. Em Nossa senhora das flores, depois de uma noite de festejos e desatinos, três das principais personagens, Nossa Senhora, Divina e Gorgui (respectivamente, um assassino, um travesti e um cafetão) perambulavam pelos guetos de Paris, em uma espécie de cortejo dionisíaco, reverenciando ao deus da tragédia, uma imagem clara de alegria:

\author{
Nossa Senhora cantava: \\ Taraboum! Pum! \\ Taraboum! Pum! Taraboum! Pum!
}

Ria enquanto cantava. Seu rosto claro e liso, com linhas e massas transtornadas por uma noite de risos, de danças, de tumulto, de vinho e de amor (a seda do vestido estava manchada), se oferecia ao dia nascente como a um beijo frio de um cadáver. Todas as rosas do seu cabelo eram de pano; no entanto, elas murcharam sobre o latão, mas ainda se mantinham em pé e compunham um jarro de flores que alguém esquecera de trocar a água. As rosas de pano estavam na verdade mortas. (GENET, 1983, p. 241-242).

As imagens descritas por Genet misturam canto, riso, violência, embriagues, erotismo. A música entoada por Nossa Senhora ressoava como onomatopeias e reproduzia os sons do retumbar de um tambor, instrumento utilizado pelos sátiros, no cortejo. $\mathrm{O}$ assassino travestiuse, trajando um vestido de seda e paramentado com rosas, uma efígie feminina, etérea; mas claramente transtornada, manchada, em êxtase, tal como uma mênade, que abandona tudo e vai atrás de Dioniso e seus seguidores, perambulando ao nascer do dia, diante dos primeiros raios de sol, ainda amalgamados com a noite orgiástica. Seus traços transpareciam a morte e a alegria. As rosas transluziam a morte e a alegria.

Em Alegria: a força maior, Clément Rosset (2000), uma das principais referências de estudos sobre o trágico, crê que o homem verdadeiramente alegre não precisa de motivos específicos para sê-lo, pois a existência, por si só, já é motivo suficiente para se alegrar. Não que não haja coisas específicas com as quais o indivíduo se satisfaça, mas, porque cada coisa é efêmera ou incompleta frente ao existir, por mais adverso que pareça. E nesse sentido, sem motivos, a alegria dispensa qualquer razão de ser; algum sentido aparente para o regozijo. É, pois, pensar “[...] na alegria geral que consiste em viver, lembrando-se que o mundo existe e que se faz parte dele.” (ROSSET, 2000, p. 14). 
Talvez por isso, a legião de desgraçados com os quais Genet nos presenteia sempre exibe vigor, vitalidade, força, vibração: alegria, portanto. Mesmo com a quantidade infindável de adversidades pelas quais passam - e que Genet também experimentou ao longo de sua vida marginalizada - sempre houve motivos para todos eles se mostrarem contentamento. Esboçar um escancarado riso afirmador.

\section{REFERÊNCIAS:}

BARRENECHEA, Miguel Angel de. Nietzsche e a alegria do trágico. Rio de Janeiro: 7 letras, 2004.

DELEUZE, Gilles; GUATTARI, Felix. O anti-Édipo, capitalismo e esquizofrenia. Lisboa: Assírio \& Alvim, 2004.

GENET, Jean. Diário de um ladrão. Rio de Janeiro: Nova Fronteira, 2005.

GENET, Jean. Nossa senhora das flores. Rio de Janeiro: Nova Fronteira, 1983.

GUATTARI, Felix. Micropolítica cartografia do desejo. São Paulo: Editora 34, 1996.

NIETZSCHE. A filosofia na idade trágica dos gregos. Lisboa: Edições 70, 1987.

NIETZSCHE. Além do bem e do mal. São Paulo: Companhia das Letras, 2005.

NIETZSCHE. Assim falava Zaratustra. Petrópolis: Vozes, 2014.

NIETZSCHE. Gaia ciência. Lisboa: Guimarães Editores, 1984.

ROSSET, Clément. Alegria: a força maior. Rio de Janeiro: Relume Dumará, 2000.

UNO, Kuniichi. A gênese de um corpo desconhecido. São Paulo: n-1, 2014. 